\title{
Entrevista com Petrona de la Cruz Cruz Fomma: Fortaleza de la Mujer Maya
}

\author{
Petrona de la Cruz Cruz \\ Entrevista realizada por Beth Lopes e Fabio Salvatti ${ }^{1}$ \\ (Tradução: Stela Fischer)
}

\section{REVISTA SALA PRETA - Como começou a sua vida no teatro e na luta das mulheres maias?}

PETRONA DE LA CRUZ CRUZ - Iniciei no teatro quase ao final dos anos 90. Quando tinha 17 anos fui sequestrada e violada. Deste estupro, fiquei grávida. Quando nasceu meu filho, eu nem sabia que estava grávida. Nunca suspeitei. Fiquei sabendo três horas antes do parto quando o médico me disse que eu ia ser mãe. Na minha comunidade não se falava de menstruação ou de relações sexuais. Era como falar de um pecado. Meus pais também não sabiam que eu estava grávida e, de repente, tive um filho. Um mês após o nascimento do meu filho, minha mãe morreu. Ela entrou em coma assim que ele nasceu. Eu passei a cuidar da casa, dos meus cinco irmãos e de meu pai. Depois de um ano da morte de minha mãe, meu pai se casou novamente e eu fui expulsa de casa porque eu já não servia mais. Eu fui trabalhar em vários lugares, de feira em feira, com o meu filho ainda bebê. Quando voltei à minha comunidade, não me aceitaram porque eu era uma mulher que havia "fracassado" e cometido um grande pecado. Como na casa de meu pai eu não era bem vinda, fui morar com uma tia. Disse a ela que eu queria continuar estudando. Ela me disse: "Você me ajuda durante a manhã e vai para a escola à tarde e te auxilio com os cuidados do seu filho. E eu não vou te pagar pelo serviço, é uma troca por eu te ajudar." Quando eu estava estudando, fiquei sabendo de um projeto sobre planejamento familiar que resultava na montagem de uma peça de teatro. Eu me integrei a este grupo, um coletivo misto de dez homens 
e duas mulheres ${ }^{2}$. A peça se chamava "Entre menos burros, mais espigas de milho" e nos apresentamos em muitas comunidades. Mas, como eu vinha de uma vida muito difícil, de um estupro, eu tinha muito medo de estar com homens. Eu pensava que eram todos iguais. No palco isso mudou, fui perdendo pouco a pouco o medo. Senti que o teatro era para mim uma terapia, cada vez que me apresentava tirava toda a dor e a tristeza que havia dentro de mim. Era um modo de continuar. O caminho que eu queria seguir era o teatro. Eu continuei fazendo teatro e nos anos 90 fui convidada para um encontro de dramaturgas em Toronto, no Canadá. Escrevi, então, minha primeira peça, Una mujer desesperada (Uma mulher desesperada) baseada em parte na minha história pessoal, da minha família e do meu povoado. E aí começou a minha trajetória como atriz e escritora.

\section{SP- Até o trabalho com este grupo você não havia estudado teatro. Você não sentiu falta de estudar mais aprofundadamente sobre o teatro?}

PETRONA- Não. Para mim o teatro começou como qualquer outra coisa, como a vida. Eu nunca fui à escola para estudar teatro. Fiz oficinas, cursos, mas nenhum curso de graduação.

\section{SP- E depois dessa experiência, como aconteceu a formação do FOMMA?}

PETRONA- Trabalhei alguns anos como atriz e escritora neste grupo e em 1992 recebi o Prêmio de Literatura Rosario Castellanos, porque fui a primeira mulher maia que começou a escrever para teatro. O Secretário de Governo me nomeou como uma das mulheres indígenas pioneiras em teatro. Os homens do grupo ficaram invejosos porque tinham muitos anos de experiência, mas nunca ganharam um prêmio. $E$ no meu primeiro trabalho de dramaturgia eu já ganhei o prêmio. Então eles me disseram que eu não podia continuar no grupo 3 . Como eu tinha escrito Una mujer desesperada queria continuar ence-

\footnotetext{
2 O grupo a que se refere Petrona de la Cruz Cruz é Sna Jtz'ibajom ou "Cultura de los Indios Mayas" (1983), cooperativa formada por escritores, atores, músicos de origem indígena da região de Chiapas que desenvolvem projetos culturais para a difusão e incentivo das tradições e cultura dos povos maias. Sobre o trabalho do grupo, consultar STEELE, Cynthia. "A woman fell into the River": negotiating female subjects in contemporary mayan theatre. In: TAYLOR, Diana \& VILLEGAS, Juan. Negotiating Performance. Gender, sexuality and theatricality in Latin/o America. Durham: Duke University Press, 1994, p. 239-255.

3 De acordo com Doris Difarnecio "Apesar de acreditar que a obra tinha méritos para que fosse montada, os membros de Sna Jtz'ibajom recusaram-se a apresentar a obra porque eram contrários em expor a violência contra as mulheres nas comunidades indígenas de sua região. Sentindo-se capazes e seguras de si mesmas, Petrona e Isabel decidem sair da Sna Jtz'ibajom e formar, com outras mulheres, um coletivo que utilizasse o teatro como principal meio de expressão. Assim nasceu o FOMMA". (DIFARNECIO, 2013, p. 100)
} 
nando a obra e eles disseram que não, que tudo o que eu tinha escrito era mentira, que não havia mais dinheiro para o projeto. A minha maior tristeza foi retirar-me do teatro. Era uma dor muito grande para mim. Depois, trabalhei por um ano em comunidades indígenas com um projeto sobre grupos de leitura, com crianças e mulheres. Era um trabalho muito bonito, mas sentia muita falta do teatro. Depois, me encontrei novamente com Isabel ${ }^{4} \mathrm{e}$ perguntei: "por que não fazemos um grupo e apoiamos as mulheres, oferecendo oficinas para as mulheres?" Então, com Isabel e com Miriam Laughlin, de Washington, começamos o que hoje é o FOMMA, em 1993. Começamos com teatro de rua, apresentando minha obra Una mujer desesperada junto com outros atores voluntários. Com as apresentações, fomos arrecadando fundos com a bilheteria para formar nosso grupo. Em 1994, constituímos o grupo já com o nome de FOMMA e desde então começamos a trabalhar.

\section{SP- Então vocês começaram trabalhando com a luta das mulheres maias. Como é o processo criativo a partir dessa diretriz?}

PETRONA- Para criar uma peça, nos reunimos, contamos diversas histórias e fazemos cenas curtas. Disso podem sair histórias pessoais, histórias de famílias, histórias de nossas comunidades. Depois as juntamos e criamos a obra.

SP- O que você sente quando incorpora e representa em sua criação um personagem ou uma situação que não concorda ou que vai contra vocể?

PETRONA- Representar um homem que é um machista, um "sem vergonha" é um pouco difícil de fazer. Prefiro representar outros papeis como, por exemplo, na obra teatral A casa de Bernarda Alba, em que interpreto Alba. Eu gosto muito dessa personagem porque daí eu tiro a minha coragem. Mas quando faço papeis masculinos é como confrontar-se com estes homens.

\section{SP- FOMMA tem mais de 17 anos, há uma evolução profissional no trabalho das atrizes nessa trajetória?}

PETRONA- Como mulheres, perdemos o medo de nos confrontarmos com os problemas do nosso cotidiano. Quando iniciamos no teatro, as pessoas nos humiIhavam, nos diziam que éramos loucas ou prostitutas. Afinal, uma mulher indígena não poderia subir num palco. Mas agora, tomamos força e enfrentamos os problemas e não nos importamos mais com o que falam. E sobre o crescimento como atrizes, a cada dia aprendemos mais.

4 Isabel Juárez Espinoza era a outra atriz que integrava o grupo Sna Jtz'ibajom, juntamente com Petrona de la Cruz Cruz. 
SP- Você trabalha como atriz, dramaturga e diretora. Você vê diferenças entre estas funções ou como as combina?

PETRONA- No meu caso, como agora tenho exercido mais a função de atriz, gosto mais que me dirijam. Eu gosto de dar meu ponto de vista. Gosto de dirigir outras pessoas, não a mim. Mas me sinto confortável nas três funções. Ao escrever eu me aproprio de tudo o que estou pensando. Quando escrevo é para alguém ler. Quando estou em cena, é para ser vista. Mas acredito ainda que escrever é mais forte do que estar em cena. Ao mesmo tempo, dirigir também é muito forte, pois tem que preparar um ator para representar um papel no palco.

SP- Para você trabalhar com teatro é também uma forma de resistir ao autoritarismo dos homens?

PETRONA- O teatro me dá forças para falar a verdade que sinto e penso. Contra ou a favor dos homens. Não quer dizer que quando um homem é contra ou a favor de algo que ele fale por todos os homens. Afinal, nem todos os homens ou mulheres são iguais.

\section{SP- Existe alguma relação ou proximidade entre o trabalho do FOMMA e os zapatistas?}

PETRONA- Não. Apenas tenho participado das mesas de debates e diálogos e acompanhado o trabalho dos zapatistas, mas nada mais além disso. Com teatro não. Já estivemos nas comunidades zapatistas apresentando algumas de nossas peças. $E$ fomos bem recebidas, afinal, também falamos coisas de interesse comum, ou seja, de uma política contra o governo, a favor da população.

\section{SP- Você está casada agora?}

PETRONA- Sim. Meu primeiro filho, que foi desse estupro, agora está com 27 anos. Meu segundo filho, que tem 17 anos, foi de um ator por quem me apaixonei. Pensei que este relacionamento seria diferente, que ele seria um homem melhor por ser ator e já conhecer o trabalho que eu vinha desenvolvendo. Achei que ele não seria tão machista, mas foi o contrário. Não nos entendemos porque ele era muito ciumento. Hoje tenho um menino de cinco anos e estou há sete anos com o meu atual esposo. Apesar de trabalhar em uma área diferente nos damos bem, ele me respeita e me incentiva. É uma relação bem diferente. Sempre que pode, ele me acompanha no meu trabalho. 
SP- Você acha que o teatro, assim como ele te fez bem, também possa fazer a diferença e resultar em mudanças na vida de outras mulheres de sua comunidade?

PETRONA- Sim, porque através do teatro, muitas mulheres desenvolvem suas reflexões e aprendizados. Acreditamos no teatro como uma forma de educar. Muitas vezes vamos às comunidades em que muitos não sabem ler nem escrever e ao assistirem nossas peças se conscientizam e aprendem. Para mim, levar o teatro às comunidades é melhor do que levar um livro. Sei que presentear alguém da comunidade com um livro não pressupõe que será lido. Ao contrário, uma peça de teatro muitos irão assistir. Eu também gosto muito de assistir e ler teatro porque aprendo.

\section{SP- E o que você tem lido de peças de teatro?}

PETRONA- Lorca, Boal, Brecht. E gosto do teatro pré-hispânico, da Sóror Juana ${ }^{5}$ porque utiliza e joga com os versos e a poesia.

\section{SP- Em quais outros lugares o FOMMA se apresentou fora do México?}

PETRONA- Quem viaja mais somos Isabel e eu, devido às restrições de recursos para as viagens. Fomos para o Canadá, Estados Unidos, Guatemala, Europa, Austrália. No Brasil, nos apresentamos em Belo Horizonte, em $2005 .{ }^{6}$

\section{SP- Você tem vontade de trabalhar como atriz em outros meios, como no cinema ou na televisão?}

PETRONA- As ilusões existem, mas eu não me comprometeria com essas outras linguagens. Trabalhar no teatro não é o mesmo que trabalhar no cinema ou na televisão. Estar na televisão não é o mesmo que estar no palco e isso me exigiria estudar muito mais. Não é um lugar em que eu me sinta bem.

SP- Além do teatro, O FOMMA tem um trabalho de conscientização e acolhimento de mulheres. $O$ teatro é uma forma de falar para e com as mulheres?

PETRONA- Sim, porque o teatro é o meio com que podemos nos introduzir nas comunidades, falar com as pessoas e ensiná-las. Levamos algo de diversão que ao mesmo tempo é uma forma de aprendizagem. A nossa entrada nas comunidades indí-

\footnotetext{
5 Sóror Juana Inés de la Cruz (1648-1695), freira, poetisa e dramaturga mexicana, foi um nome importante para a literatura barroca do país.

6 O FOMMA participou do $5^{\circ}$. Encontro do Instituto Hemisférico, Performances e raízes: práticas indígenas contemporâneas e mobilizações comunitárias, realizado em Belo Horizonte, em 2005.
} 
genas e campesinas acontece mediante a licença das autoridades de cada povoado. Ou ainda, muitas vezes somos convidadas por outros grupos que nos conhecem. E se querem vir até San Cristóbal, estamos de portas abertas para receber as pessoas.

\section{SP- Como Doris Difarnecio ${ }^{7}$ chegou até vocês?}

PETRONA- Doris chegou por meio do contato com Miriam Laughlin. Ela veio para nos dirigir e começamos a trabalhar juntas. Viria apenas por um ou dois meses para realizarmos uma peça teatral. E quando nos associamos ao Hemisférico ${ }^{8}$, Diana (Taylor) nos perguntou quem queríamos para nos dirigir. E Doris passou a ser a nossa diretora oficial.

\section{SP- Como vocês conheceram a Diana Taylor?}

PETRONA- Em uma conferência nos Estados Unidos ou no México, não me lembro ao certo. Trabalhávamos com o outro grupo ${ }^{9}$ que também viajava muito ao exterior com seus trabalhos. Ainda não éramos o FOMMA.

\section{SP- E agora a situação econômica de vocês está melhor que antes?}

PETRONA-Sempre temos dificuldades de realizar projetos ou de fazer parcerias para arrecadar recursos. Nossa sede foi uma conquista muito importante. Com este espaço que é alugado, temos que conseguir fundos para nos manter e para seguir com o FOMMA.

\section{SP- Quais outras atividades vocês realizam no FOMMA além do teatro?}

PETRONA- A principal é o teatro. Mas também temos oficinas de costura, panificação, computação, alfabetização, línguas maias, oficinas para crianças de artes,

\footnotetext{
7 De acordo com Diana Taylor, desde 1999, FOMMA vem trabalhando juntamente com a diretora teatral colombiana Doris Difarnecio, que as ajudou a criar as seguintes montagens: Cresci sólo con el amor de mi madre, La voz y la fuerza de la mujer, Soledad y Esperanza, La bruja monja, Viva la Vida, La Viuda de Antonio Ramales, Dulces y amargos sueños. (http://www.casa.cult.cu/publicaciones/revistaconjunto/145/taylor.pdf).

8 O Hemispheric Institute e o FOMMA formaram uma parceria para a criação do Centro Hemisférico em Chiapas (2008-2013). Primeiro centro cultural e de pesquisa regional do Instituto, ofereceu diversas atividades artísticas e de formação, como conferências, cursos, debates e apresentação de performances, vídeos, fotografia. Após cinco anos de parceria, "as duas organizações decidiram fechar o Centro, e agora FOMMA usa o espaço para seus próprios projetos. O Instituto Hemisférico e FOMMA continuarão colaborando informalmente, como faziam antes da construção do prédio", de acordo com o site do Hemispheric Institute (http://hemisphericinstitute.org/ hemi/pt/centros).

9 Sna Jtz'ibajom, grupo citado anteriormente.
} 
máscaras. As mulheres do FOMMA ensinam as outras mulheres. Nós mesmas oferecemos as oficinas. Eu ministro a oficina de línguas maias, tzoltil. Em nossa comunidade temos muitas pessoas que falam, mas que não sabem escrever na língua indígena. É uma atividade muito importante porque, agora, uma nova lei do governo mexicano exige que todos devem falar e escrever para conseguir empregos. $E$ há muitos espaços de colocação profissional, como tradutores ou professores, por exemplo. Muitos se iniciam no mercado de trabalho primeiramente dando aulas para crianças.

\section{SP- Gostaria de encerrar perguntando o que vocês gostariam de ter no FOMMA que não tiveram até agora?}

PETRONA- Ter a vontade de seguir vivendo. Seguir conhecendo mais pessoas e fundações que apoiem nosso trabalho.

\section{Referências}

DIFARNECIO, Doris. Teatro Popular Criado Pelas Mulheres da Fortaleza da Mulher Maya (FOMMA) nos Altos de Chiapas, México. Revista aSPAs, Brasil, v. 3, n. 1, p. 94-104, dez. 2013. ISSN 2238-3999. Disponível em: <http://revistas.usp.br/aspas/article/view/68389>. Acesso em: 14 Mar. 2014. doi:http://dx.doi.org/10.11606/issn.2238-3999.v3i1p94-104.

STEELE, Cynthia. A woman fell into the River: negotiating female subjects in contemporary mayan theatre. In: TAYLOR, Diana \& VILLEGAS, Juan. Negotiating Performance. Gender, sexuality and theatricality in Latin/o America. Durham: Duke University Press, 1994, p. 239-255.

TAYLOR, Diana. La bruja monja: Petrona de La Cruz Cruz e Isabel Juárez Espinosa. Disponível em: http://www.casa.cult.cu/publicaciones/revistaconjunto/145/taylor.pdf (Acesso em junho de 2013).

\section{Sites}

http://fomma-chiapas.org/

http://hemisphericinstitute.org/hemi/pt/entrevistas/itemlist/category/69-fomma

Recebido em 17/03/2014

Aprovado em 30/04/2014

Publicado em 25/06/2014 